\title{
Impact of Implementing Nursing Protocol on Respiratory Function of Elderly Patients' with Chronic Obstructive Pulmonary Disease
}

\author{
Martha, M. Labieb ${ }^{1}$, Safaa, A. Mohamed ${ }^{2}$, Nermeen, M. Abd El-Aziz ${ }^{3}$, Ali, A. Hassan ${ }^{4}$ \& Heba, M. Fahmy ${ }^{5}$ \\ Assistant Lecturer in Gerontological Nursing department, Faculty of Nursing, Assiut University, Egypt. \\ Professor of Community and Family Health Nursing, Faculty of Nursing, Assiut University, Egypt. \\ Assistant Professor of Gerontological Nursing, Faculty of Nursing, Assiut University, Egypt. \\ Assistant Professor of Chest Diseases \& Tuberculosis, Faculty of Medicine, Assiut University, Egypt \\ 5. Lecturer of Gerontological Nursing, Faculty of Nursing, Assiut University, Egypt.
}

\begin{abstract}
Background: Chronic Obstructive Pulmonary Disease (COPD) is a common respiratory disease interferes with basic function of breathing of elderly. Aim: To evaluate the impact of implementing nursing protocol on respiratory function of elderly patients' with COPD. Subjects \& methods: Quasi - experimental research design was utilized to conduct this study in Chest Diseases Departments at the Main Assuit University Hospital. A purposive sample of 169 elderly patients with COPD (87 study\& 82 control groups) was participated. Three tools were used includes: 1 st tool: Elderly patients assessment sheet, it includes 2 parts (Socio-demographic\& health history and Bristol COPD knowledge sheet). 2nd tool observational check lists: used to assess the practice of elderly includes (breathing \& coughing exercise, inhaler technique and incentive spirometer). The 3rd tool respiratory function assessment sheet used to evaluate (dyspnea scale, $\mathrm{SaO} 2$, respiratory rate). Results: $75.9 \%$ were male, $63.1 \%$ were illiterate and vast majority were living in rural area. $97 \%$ of participant had poor knowledge \& practice pre implementation. There were statistically significant differences between total score of elderly patients' knowledge\& practice and respiratory function outcomes after application of nursing protocol ( $2 \& 6$ months). Conclusion: Most of the studied elderly had poor knowledge \&practice and sever dyspnea in pre-test after application the nursing protocol were significant improved respectively. Recommendations: Frequent patient education, home visit and telephone follow up is very essential to manage COPD patients.
\end{abstract}

\section{Keywords: COPD, Elderly, Nursing Protocol \& Respiratory Function Outcomes.}

\section{Introduction}

Aging is a gradual, continuous process of natural changes that begins in early adulthood and associated with irreversible decline in organ function that occur over time even in the absence of injury, illness, or poor lifestyle choices (Tudorache et al., 2017).The number of older persons those aged 60 years or over is rising from 962 million globally in 2017 to 1.4billion in 2030 also population aged 60 or above is growing about 3\% per year (World Population Prospects, 2018). According to Central Intelligence Agency, (2020) reported that, Egypt's elderly population had reached 6.5 million; 3.5 million males and 3 million females and will increase in 2050 to 18.1 million elderly. Also, the Egyptian life expectance 2019 is 71.90 years: 68.2for male and 73.0 years for female.

Age related respiratory system changes that occur with aging are complex and characterized by a decline in pulmonary function, a reduction in muscular strength, an increase in inflammatory cells in bronchial tissue, increased stiffness and reduced compliance of the thoracic wall. These are mechanical and cellular changes lead to increase prevalence of chronic obstructive pulmonary disease (COPD) in the elderly (Hun Lee et al., 2016).
COPD is a disease in the lung which the airways become narrowed. This leads to limitation in the flow of air and causing shortness of breath. It includes chronic bronchitis and emphysema which leads to the destruction of lung and airways. The most common symptoms of COPD are breathlessness, chronic cough, and sputum production. COPD patients also frequently experience exacerbations, that is, serious episodes of increased breathlessness, cough and sputum production that last from several days to a few weeks (Global Initiative for Chronic Obstructive Lung Disease (GOLD), 2019).

Nurse Protocol means is a written document mutually agreed upon and signed by a nurse and a licensed physician, by which the physician delegates to that nurse the authority to perform certain medical acts Scullion, 2018). The protocol is a document that's developed to guide decision-making around specific issues, whether it is how to diagnose, treat and care for someone with a specific condition, procedures to follow to or how report that a specific event has taken place. It's like a 'guidebook' for health care staff, helping them to make sure they're taking the right action to get the best outcomes and avoid any possible problems (Royal College of Nursing, 2016). 
Nursing protocol for patients with COPD should be applied in chest units periodically in order to improve knowledge, practice and clinical outcomes for those patients. The primary goals of nurse for COPD management are slowing disease progression, relieving symptoms, improving exercise tolerance, preventing and treating complications, promoting patient's participation in care, preventing and treating exacerbation and reducing mortality risk (Mohamed et al., 2017).

\section{Significance of the study}

COPD is the third cause of death and the fifth cause of disability adjusted life years in 2020.The prevalence of COPD increases with age, with a fivefold increased risk reported for those aged over 65 years. It affects more than 300 million people worldwide, three million deaths per year and more than $90 \%$ of COPD deaths occur in low and middle income countries Roberto et al., 2016).In Egypt, COPD is a rising significant health problem and the prevalence of COPD among high-risk individuals in Egypt was estimated to be about $10 \%$ as per Global Initiative for Chronic Obstructive Lung Disease (Said et al, 2015). Assuit Main University Hospital unpublished thesis, in 2017 the number of patients diagnosed with COPD from 60 years old and above were nearly about 400 patients (Mohammad et al., 2018).

COPD is not curable, but management can relieve symptoms and reduce the risk of death. The airways become obstructed, making it hard to breath and progressively immobile due to dyspnea and fatigue. Patients' health status is negatively affected by disease exacerbations, progressive loss of lung function, unsatisfactory therapeutics. Prompt followup of COPD patients has been linked with reduced rates of readmission, emergency department use, and death (Li etal, 2016).

\section{Aim of the study}

To evaluate the impact of implementing nursing protocol on respiratory function of elderly patients' with chronic obstructive pulmonary disease.

\section{Study hypothesis}

1- There was lacking of elderly patients' knowledge and practice levels about COPD.

2- Mean scores of knowledge and practice for COPD elderly patients' in study group improved than in control group after follow up nursing protocol application.

3- Dyspnea grades of COPD elderly patients' in study group reduced and improved than in control group after follow up nursing protocol application.
Definition of nursing protocol: It means a written document mutually agreed upon and signed by a nurse and a licensed physician, by which the physician delegates to that nurse the authority to perform certain medical acts (Scullion, 2018).

Setting: This study was conducted in the Chest Diseases Departments at the Main Assuit University Hospital. This setting provides services for patients with chest diseases for all Upper Egypt from Mina to Aswan.

\section{Sample}

Sample size calculated according to the prevalence rate during one year (2017), where the total number of admission of COPD elderly patients' was 400 cases and taken $50 \%$ from the total number equal 200 COPD elderly patients were enrolled in the study. The patients are divided into two equal groups (study and control groups) 100 for each group. Drop out occurred during data collection period and 87 study patients \& 82 control) continued the study. The control group received the usual hospital routine care only, while the study group received the usual hospital routine care and a nursing protocol.

\section{Tools of the study}

Three tools used in this study: the $1^{\text {st }}$ tool elderly Patients' assessment sheet, the $2^{\text {nd }}$ tool patients' observational checklists and $3^{\text {rd }}$ tool respiratory function outcomes assessment sheet).

Tool (1): Patients' assessment sheet, it included 2 parts: Part 1: Socio-demographic characteristics\& health history of elderly

A- Socio-demographic characteristics (El-Gilany et al., 2012): El-Gilany scale used to assess sociodemographic characteristics includes: seven domain, educational and cultural domain for both (husband and wife), occupation domain, family domain, economic domain, family possessions domain, home sanitation domain and health care domain.

Scoring system: The socioeconomic status assessed using a scale comprised seven domains with a maximum score of 84 and a higher score indicating better socioeconomic status. Socioeconomic scores were classified into 4 levels, scores < 42 (very low), $42<63$ (low), $63<71.4$ (moderate) and $71.4-84$ (high social level).

Validity and reliability: The socioeconomic status scale is valid and reliable $(\mathrm{r}=0.93)$.

\section{B- Heath history includes}

1. Present history as present complaints, duration of disease, and date of current admission \& date of current hospital discharge.

2. Past history as previous hospital admissions, previous chest surgery and chronic diseases as hypertension, diabetes, liver and kidney disease ......etc). 
3. Family history of COPD or other chronic respiratory diseases.

4. Patient exposure to risk factors as environmental or occupational hazards.

Part 2: Bristol COPD Knowledge Questionnaire (BCKQ) (White et al. 2006): It used to assess level of knowledge regarding COPD before and after application of nursing protocol which included 13 domains, each consisted of five items. (1) disease pathophysiology, (2) risk factors, (3) symptoms, (4) cause of dyspnea, (5) sputum, (6) exacerbations, (7) exercise, (8) smoking, (9) vaccination, (10) bronchodilators, (11) antibiotics, (12) oral steroid therapy and (13) inhaled steroid therapy.

Validity and reliability: The BCKQ demonstrated good test-retest reliability of $\mathrm{r}=0 \_71$. Thenew questions demonstrated good test-retest reliability of $\mathrm{r}=0 \_87$ (White et al. 2006).

The researchers added others questions for assessed knowledge to meet purpose of the study. It included questions about structure \& age-related changes in respiratory system, also healthy life style used to improve respiratory function for COPD elderly patients such as good nutrition, healthy sleeping, and measures to reduce respiratory infection\& air ways irritation and difficulty in breathing based on the following literature (Knight \& Nigam, 2017, Miller, 2019, Fiona, 2016, Bowdish, 2019, Yorke et al., 2017, Smeltzer \& Bare, 2016, Rawal \& Yadav, 2015, Du et al., 2018 \& Miravitlles \& Anzueto., 2017).

Scoring system: Scoring system of patient's knowledge was done as follows, each correct answers was given one grade, while no answer or did not know was scored zero. The scores obtained for each set of questions was summed up to get the total score for patient's knowledge. Total score of Bristol COPD Knowledge Questionnaire ranged from 0-65 points + the questions added by researchers was 72points. The total knowledge score ranged from 0 137.The total level of knowledge was categorized as follows: less than or equal to $50 \%$ was graded as poor or unsatisfied, $50 \%$ to less than $75 \%$ score was graded as fair or satisfied, and greater than or equal to $75 \%$ score was graded as good (Ibrahim and Abd El-Maksoud, 2018).

Tool II: Observational Check lists (Pre/ Posttest): This tool used to assess the practice of elderly patients for following skills on his admission to hospital and after application of sessions:-

A. Breathing retraining exercise (Pursed lip breathing and Diaphragmatic breathing):It used to assess and help patient to adapt dyspnea, decreasing the work of breathing, improving oxygenation, increasing the efficiency of breathing patterns and promoting patient control of breathing (Sarkar et al., 2019).

B. Inhaler techniques (Using a metered- dose inhaler and using a dry powder inhaler with capsule): It used to assess how the COPD patients use their inhalers properly (American Lung Association, 2018).

C. Airway clearance (Breathing and coughing exercise): It used to assess the body's ability to clearing mucus from the lungs. Controlled coughing loosens, moves mucus and is most effective method for COPD patients' to reduce risk of infection if the mucus isn't cleared (Dimitrova et al., 2017).

D. Body position to reduce shortness of breath (Sitting, Standing and sleeping position: It used to assess the body's ability to adjust with dyspnea in different position (Smeltzer and Bare, 2016).

Scoring system: Scoring of the checklist of each item was made using 2-point ranging from 0 to 1 , where " 0 " indicates that the skill was not done and "1" done. Each technique was assigned a score, with a total score of 43 . The total score was distributed as for breathing retraining exercise was 9 grades, airway clearance techniques was 6 grades, body position to reduce dyspnea 11 grades for three positions and for using inhaler was (17) grades (Mohamed et al., 2017).

The total level of practice score was categorized as: $<50 \%$ of the total score was considered poor, from $50 \%$ to less than $75 \%$ was considered fair, and from $75 \%$ and more was considered good (Ibrahim \& Abd El-Maksoud, 2018).

Tool III: Respiratory function assessment sheet; it will include five parts (Pre/ Post-test): It used to evaluate the respiratory function for COPD elderly patients'.

Part 1: A modified medical research council dyspnea a scale: The modified MRC scale was used to evaluate dyspnea in daily living. It includes five grades (0-4) of various physiological activities that are graded from none (0) to the highest level of dyspnea. The descriptions were as follows: (0) none dyspnea, (1) mild dyspnea, (2) moderate dyspnea, (3) severe dyspnea, and (4) very severe dyspnea (Nishiyamaet al., 2010).

Part 2: Respiratory rate for elderly: Respiratory rates generally are faster and shallower in elderly: a normal rate is $16-25$ breaths per minute in elderly (Meiner, 2018).

Part3: Pulse oximetry: It is a small sensor that is placed on a finger and sends out light pulses. An oxygen saturation level of 95-100 percent is 
considered normal for most healthy elderly people. A level of 92 percent indicates potential hypoxemia, or deficiency in oxygen reaching tissues in the body (Jubran, 2015).

Part 4: Incentive Spirometer:The incentive spirometer is designed to encourage the user to take deep breath and help patient to clearance the sputum from the lungs.Air flows into single channel, when it passes through the chamber; it raises each of the three balls depending on the flow inhaled per second. Flow rates $600 \mathrm{ml} / \mathrm{sec}, 900 \mathrm{ml} / \mathrm{sec}$, and $1200 \mathrm{ml} / \mathrm{sec}$ by using different colors of ball for easy identification of the flow rates (Restrepo et al., 2011).

Part 5: Peak flow meter. A peak flow meter is a portable, inexpensive and hand-held device used to measure how air flows from the lungs. In other words, the meter measures the ability to push air out of the lungs. List a scale, starting with zero (0) liters per minute $(\mathrm{L} / \mathrm{min})$ ending with $800 \mathrm{~L} / \mathrm{min}$ at the top (American Lung Association, 2018).

\section{Method}

Administrative design: An official letter approval was obtained from the Dean of the Faculty of Nursing, to the head of Chest disease Department. This letter included a permission to carry out the study and explained the purpose and nature of the study.

\section{Pilot study}

Pilot study was carried out before starting of data collection on $10 \%$ of elderly patients in a selected setting to examine the applicability, the feasibility and clarity of the developed tools. Also to estimate the time needed and not excluded from the study.

\section{Data collection}

The nursing protocol phases: The researcher developed the nursing protocol through four phases (assessment, planning, implementation and evaluation phase).

\section{General objective}

At the end of this protocol, the patients are expected to be able to improved respiratory function outcomes of COPD.

\section{Specific objectives}

After completing this protocol; the COPD elderly patients' will be able to:

1. Identify organs and function of respiratory system.

2. Describe age related changes on respiratory system

3. Acquire knowledge about COPD nature.

4. Explain the risk factors and causes of COPD among elderly.

5. List signs and symptoms of COPD.

6. Identify medications of COPD.
7. Practice inspiratory muscle training, pursed-lip breathing, diaphragmatic breathing, airway clearance techniques, using inhaler in correct way and incentive spirometer.

8. Enumerate the large benefits of breathing exercise.

A- Assessment phase

- The researcher meet the elderly in the chest disease department, introduced self and explain purpose of the study then, asked the elderly to participate in the study after assuring the confidentiality of their data.

- Oral consent taken from the elderly patients after explanation the purpose of the study.

- The assessment was done in all the study sample 200 elderly patients (100 study group and 100 control group) using all study tools (Pre-test).

- Drop out occurred during data collection period 169 (87 study \& 82 control) continued the study.

- The length of interview to fill the interview sheet without application nursing protocol (about 30 to 40 minutes) for each patient in both groups depending upon their understanding and response. (Pretest).

\section{B- Planning phase}

- The arrangement of conducting the nursing protocol was done during this phase. The nursing protocol was given to one elderly per day. Other facilities were checked and arranged during this phase as teaching place, audiovisual aids and handout.

- Teaching time: the time of teaching was decided according to coordination between the researcher and each elderly patient individually, the researcher attends every day from patient admission until discharge from the about 80-90 min every day in different periods according to the respond of patients.

- Teaching place: The study program was conducted in the Chest Disease Department (Inpatient).

- Teaching methods and materials: it was prepared before implementing the nursing protocol, to prepare simple teaching instruments and audiovisual aids to be used; as colored picture, video on lap top and booklet. Equipment for practical application as incentive spirometer, peak flow meter and inhaler devices.

C- Implementation phase

1- The researcher prepared educational booklet which used as a hand out, videos and pictures on lab top for elderly who shared in the nursing 
protocol to study group. The education session was given in four sessions to improve elderly knowledge.

2- Each patient also trained three sessions to practice coughing \&breathing exercise \& incentive spirometer, performed by the investigator for each patient and taught to one of family member (resident).

3- Each patient in study group saw by the investigator during hospitalization to be sure that the instructions are followed correctly. Correction, reinstruction and re-demonstration offered.

4- The average number of elderly which interviewed and application of the nursing protocol was 10 cases per week, and 30-35 elderly patients / month.

5- The telephone numbers of the elderly patients taken to check with them their consistency with nursing protocol to continue follow up.

6- The nursing protocol application and the follow-up period started from February2019 to December2019.

D: Evaluation phase

- Immediate post-test was done immediately after applying the nursing protocol to evaluate knowledge and practice through using the study tool (post-test).

- Follow up post-test was done after 2 and 6 months from applying the nursing protocol to evaluate both study and control groups done at the out-patients clinics at Main Assuit University Hospital to determine the effect of nursing protocol on respiratory function, oxygen saturation, respiratory rate, and evaluate also their knowledge and practice through using the study tools.

- Comparison of each patient's findings with the preceding one and comparison between control and study group's findings were done to evaluate the effect of nursing protocol on the respiratory function and related outcomes.

- Drop out occurred during data collection period (87 study \& 82 control) continued the study. For study group (13 COPD elderly patients from 100 cases in study group; 6 patients died \&7patients lack of communication and problems in transportation to continue follow up).

- For control group (18COPD elderly patients from 100 cases ( 8 patients died\&10 patient's lack of communication and problems in transportation to continue follow up.

\section{Limitation of the study}

1- Difficult patient adherence about follow up programs during six months.

\section{Statistical Analysis}

The data were tested for normality using the Kolmogorov-Smirnov test and for homogeneity variances prior to further statistical analysis. Categorical variables were described by number and percent $(\mathrm{N}, \%)$, where continuous variables described by mean and standard deviation (Mean, SD). Chi-square test and fisher exact test used to compare between categorical variables while compare between continuous variables by t-test $\boldsymbol{\&}$ Anova test. A two-tailed $\mathbf{p}<0.05$ was considered statistically significant. Spearman's correlation coefficient was used to test correlation between variables. All analyses were performed with the IBM SPSS 20.0 software. Graphs were done for data visualization and using Microsoft Excel 2010.

\section{Ethical consideration}

Research proposal was approved from Ethical Committee in the Faculty of Nursing. There is no risk for study subject during application of the research. Patients advised of their right to withdraw from the study at any point. Patients coded for data entry so that their names could not be identified. Verbal consent from the elderly patients to participate in the study was obtained after explanation of the study purpose. 


\section{Results}

Table (1): Distribution of COPD elderly patients' regarding to socio-demographic characteristics at Assuit University Hospital, 2019.

\begin{tabular}{|c|c|c|c|c|c|}
\hline \multirow{2}{*}{ Items } & \multicolumn{2}{|c|}{ Study(n=87) } & \multicolumn{2}{|c|}{ Control(n=82) } & \multirow{2}{*}{ P. value } \\
\hline & No. & $\%$ & No. & $\%$ & \\
\hline \multicolumn{6}{|l|}{ Age } \\
\hline $60 \leq 65$ year & 59 & 67.8 & 49 & 59.8 & \multirow{3}{*}{0.276} \\
\hline$>65$ year & 28 & 32.2 & 33 & 40.2 & \\
\hline Mean \pm SD & \multicolumn{4}{|c|}{$65.08 \pm 5.12$} & \\
\hline \multicolumn{6}{|l|}{ Sex } \\
\hline Male & 66 & 75.9 & 58 & 70.7 & \multirow{2}{*}{0.451} \\
\hline Female & 21 & 24.1 & 24 & 29.3 & \\
\hline \multicolumn{6}{|l|}{ Marital status } \\
\hline Married & 74 & 85.1 & 55 & 67.1 & \multirow{2}{*}{$0.006 * *$} \\
\hline Widow & 13 & 14.9 & 27 & 32.9 & \\
\hline \multicolumn{6}{|l|}{ Educational level } \\
\hline Illiterate & 54 & 62.1 & 60 & 73.2 & \multirow{5}{*}{0.356} \\
\hline Read and write & 17 & 19.5 & 9 & 11.0 & \\
\hline Primary & 4 & 4.6 & 6 & 7.3 & \\
\hline Secondary "3-5" years & 8 & 9.2 & 5 & 6.1 & \\
\hline Intermediate 2 year Institute & 4 & 4.7 & 2 & 2.4 & \\
\hline \multicolumn{6}{|l|}{ Occupation } \\
\hline Non-working "house wife" & 20 & 23.0 & 24 & 29.3 & \multirow{6}{*}{$0.009 * *$} \\
\hline Unskilled manual worker & 8 & 9.2 & 9 & 11.0 & \\
\hline Skilled manual worker "farmer" & 39 & 44.8 & 33 & 40.2 & \\
\hline Trades- business & 5 & 5.7 & 14 & 17.1 & \\
\hline Semi-professional- clerk & 11 & 12.6 & 2 & 2.5 & \\
\hline Professional & 4 & 4.6 & 0 & 0.0 & \\
\hline \multicolumn{6}{|l|}{ Residence } \\
\hline Urban slum & 0 & 0.0 & 2 & 2.4 & \\
\hline Rural & 71 & 81.6 & 74 & 90.2 & 0.039* \\
\hline Urban & 16 & 18.4 & 6 & 7.3 & \\
\hline \multicolumn{6}{|c|}{ El-Gilany scale for socioeconomic level } \\
\hline Very low social level & 74 & 85.1 & 78 & 95.1 & 0.055 \\
\hline Low social level & 13 & 14.9 & 4 & 4.9 & \\
\hline Mean \pm SD & \multicolumn{2}{|c|}{$21.8 \pm 9.8$} & \multicolumn{2}{|c|}{$20.83 \pm 3.24$} & 0.369 \\
\hline
\end{tabular}


Table (2): Present health history of COPD elderly patients' at Assuit University Hospital, 2019.

\begin{tabular}{|c|c|c|c|c|c|}
\hline \multirow{2}{*}{ Items } & \multicolumn{2}{|c|}{$\operatorname{Study}(n=87)$} & \multicolumn{2}{|c|}{$\operatorname{Control}(n=82)$} & \multirow{2}{*}{ P. value } \\
\hline & No. & $\%$ & No. & $\%$ & \\
\hline \multicolumn{6}{|l|}{ 1-Present complain \# } \\
\hline Dyspnea & 87 & 100.0 & 82 & 100.0 & - \\
\hline Cough & 87 & 100.0 & 82 & 100.0 & - \\
\hline Wheeze & 77 & 88.5 & 68 & 82.9 & 0.299 \\
\hline Fatigue & 56 & 64.4 & 51 & 62.2 & 0.770 \\
\hline Anorexia & 42 & 48.3 & 55 & 67.1 & 0.014 \\
\hline Chest pain & 8 & 9.2 & 8 & 9.8 & 0.901 \\
\hline \multicolumn{6}{|l|}{ 2- Characteristics of cough and sputum } \\
\hline Productive & 87 & 100.0 & 82 & 100.0 & - \\
\hline \multicolumn{6}{|l|}{ Time of cough } \\
\hline All day & 66 & 75.9 & 57 & 69.5 & \multirow[t]{3}{*}{$0.001 * *$} \\
\hline In the morning & 11 & 12.6 & 1 & 1.2 & \\
\hline Nocturnal & 10 & 11.5 & 24 & 29.3 & \\
\hline \multicolumn{6}{|l|}{ Color of sputum } \\
\hline White & 62 & 71.3 & 62 & 75.6 & \multirow[t]{3}{*}{0.813} \\
\hline Yellow & 19 & 21.8 & 15 & 18.3 & \\
\hline Green & 6 & 6.9 & 5 & 6.1 & \\
\hline \multicolumn{6}{|l|}{ Consistency of sputum } \\
\hline Thick & 85 & 97.7 & 79 & 96.3 & \multirow[t]{2}{*}{0.602} \\
\hline Thin & 2 & 2.3 & 3 & 3.7 & \\
\hline \multicolumn{6}{|l|}{ Amount of sputum (ml/day) } \\
\hline Large & 48 & 55.2 & 47 & 57.3 & \multirow[t]{3}{*}{0.390} \\
\hline Moderate & 37 & 42.5 & 30 & 36.6 & \\
\hline Small & 2 & 2.3 & 5 & 6.1 & \\
\hline \multicolumn{6}{|l|}{$\begin{array}{l}\text { 3-Length of hospital stay for current hospital } \\
\text { admission }\end{array}$} \\
\hline$\leq 10$ days & 32 & 36.78 & 17 & 20.73 & \multirow[t]{3}{*}{ 0.049* } \\
\hline 10 - 20 days & 48 & 55.17 & 53 & 64.64 & \\
\hline$>20$ days & 7 & 8.05 & 12 & 14.63 & \\
\hline Mean \pm SD & \multicolumn{2}{|c|}{$12.82 \pm 4.8$} & \multicolumn{2}{|c|}{$15.12 \pm 4.79$} & $0.002 * *$ \\
\hline $\begin{array}{l}\text { 4-Patient seeks medical advice during } 6 \text { months } \\
\text { (Follow up period). }\end{array}$ & \multicolumn{2}{|c|}{$3.39 \pm 1.22$} & \multicolumn{2}{|c|}{$7.52 \pm 2.3$} & $<0.001 * *$ \\
\hline \multicolumn{6}{|l|}{ 5-Body Mass Index } \\
\hline BMI less than 19 & \multicolumn{2}{|c|}{1} & \multicolumn{2}{|c|}{1.1} & \multirow{4}{*}{0.412} \\
\hline BMI 19 to less than 21 & \multicolumn{2}{|c|}{19} & \multicolumn{2}{|c|}{21.8} & \\
\hline BMI 21 to less than 23 & \multicolumn{2}{|c|}{19} & \multicolumn{2}{|c|}{21.8} & \\
\hline BMI 23 or greater & & & & & \\
\hline
\end{tabular}

\# More than one answer

Table (3): Past health history of COPD elderly patients' at Assuit University Hospital, 2019.

\begin{tabular}{|l|c|c|c|c|c|}
\hline \multirow{2}{*}{\multicolumn{1}{c|}{ Items }} & \multicolumn{2}{c|}{ Study(n=87) } & \multicolumn{2}{c|}{ Control(n=82) } & \multirow{2}{*}{ P. value } \\
\cline { 2 - 7 } & No. & \% & No. & \% & \\
\hline 1- Comorbidities \# & & & & & \\
\hline Hypertension & 57 & 65.5 & 52 & 63.4 & 0.775 \\
\hline Diabetes Mellitus & 41 & 47.1 & 38 & 46.3 & 0.919 \\
\hline GIT disorders & 10 & 11.5 & 24 & 29.3 & $\mathbf{0 . 0 0 4} * *$ \\
\hline Musculoskeletal problems & 7 & 8.0 & 9 & 11.0 & 0.516 \\
\hline
\end{tabular}




\begin{tabular}{|c|c|c|c|c|c|}
\hline \multirow{2}{*}{ Items } & \multicolumn{2}{|c|}{ Study(n=87) } & \multicolumn{2}{|c|}{ Control(n=82) } & \multirow{2}{*}{ P. value } \\
\hline & No. & $\%$ & No. & $\%$ & \\
\hline Liver diseases & 7 & 8.0 & 8 & 9.8 & 0.696 \\
\hline Renal disorders & 3 & 3.4 & 7 & 8.5 & 0.161 \\
\hline None & 12 & 13.8 & 13 & 15.9 & 0.706 \\
\hline \multicolumn{6}{|l|}{$\begin{array}{ll}\text { 2- Smoking } \\
\text { A- } & \text { Smoking habits }\end{array}$} \\
\hline Smoker & 61 & 70.1 & 58 & 70.7 & \multirow{3}{*}{0.928} \\
\hline Non smoker & 10 & 11.5 & 8 & 9.8 & \\
\hline Passive smoker & 16 & 18.4 & 16 & 19.5 & \\
\hline \multicolumn{6}{|l|}{ B- Types of smoking } \\
\hline Cigarette & 31 & 50.8 & 30 & 51.7 & \multirow{3}{*}{0.379} \\
\hline Shisha & 28 & 45.9 & 28 & 48.3 & \\
\hline Other & 2 & 3.3 & 0 & 0.0 & \\
\hline \multicolumn{6}{|l|}{ C- Smoking index (pack per year) } \\
\hline Mild smoker $\geq 10$ packs & 0.0 & 0.0 & 0.0 & 0.0 & \multirow{3}{*}{0.789} \\
\hline moderate smoker $\geq 10-20$ packs & 5 & 5.7 & 4 & 4.9 & \\
\hline Heavy smokers $\geq 20$ packs & 56 & 64.4 & 54 & 65.9 & \\
\hline Mean \pm SD & \multicolumn{2}{|c|}{ Mean \pm SD } & \multicolumn{2}{|c|}{ Mean \pm SD } & \\
\hline 3-No. of hospital admissions (during last year) & \multicolumn{2}{|c|}{$3.09 \pm 1.03$} & \multicolumn{2}{|c|}{$2.88 \pm 1.17$} & 0.208 \\
\hline $\begin{array}{l}\text { 4-No. of emergency unit admissions (during last } \\
\text { year) }\end{array}$ & \multicolumn{2}{|c|}{$4.91 \pm 1.39$} & \multicolumn{2}{|c|}{$4.51 \pm 1.29$} & 0.057 \\
\hline 5-No. of respiratory infection (during last year) & \multicolumn{2}{|c|}{$2.77 \pm 0.69$} & \multicolumn{2}{|c|}{$2.77 \pm 0.81$} & 0.987 \\
\hline 6- Duration of COPD/year (Mean \pm SD) & \multicolumn{2}{|c|}{$7.7 \pm 3.6$} & \multicolumn{2}{|c|}{$7.27 \pm 3.81$} & 0.448 \\
\hline
\end{tabular}

\# More than one answer.

Table (4): Distribution of COPD elderly patients' regarding to risk factors at Assuit University Hospital, 2019.

\begin{tabular}{|l|c|c|c|c|c|}
\hline \multirow{2}{*}{\multicolumn{1}{|c|}{ Items }} & \multicolumn{2}{c|}{ Study(n=87) } & \multicolumn{2}{c|}{ Control(n=82) } & \multirow{2}{*}{ P. value } \\
\cline { 2 - 5 } & No. & $\mathbf{\%}$ & No. & \% & \\
\hline A-Occupational hazards exposure \# & & & & & \\
\hline Dust\& smoke & 85 & 97.7 & 82 & 100.0 & 0.167 \\
\hline Vehicle vapors & 46 & 52.9 & 47 & 57.3 & 0.562 \\
\hline Chemical vapors & 34 & 39.1 & 21 & 25.6 & 0.062 \\
\hline Grains & 12 & 13.8 & 20 & 24.4 & 0.079 \\
\hline Feathers of birds & 6 & 6.9 & 8 & 9.8 & 0.500 \\
\hline Not exposed & 0 & 0.0 & 1 & 1.2 & 0.302 \\
\hline B-Environmental hazards exposure \# & & & & & \\
\hline Dusts due to agricultural crops & 81 & 93.1 & 71 & 86.6 & 0.159 \\
\hline Smoke inside house & 73 & 83.9 & 74 & 90.2 & 0.221 \\
\hline Tobacco smoke & 65 & 74.7 & 62 & 75.6 & 0.893 \\
\hline Pesticides & 59 & 67.8 & 44 & 53.7 & 0.059 \\
\hline Household chemicals & 53 & 60.9 & 43 & 52.4 & 0.266 \\
\hline Dusts due to cleaning house & 47 & 54.0 & 36 & 43.9 & 0.188 \\
\hline Asbestos & 17 & 19.5 & 13 & 15.9 & 0.531 \\
\hline Factory smoke & 12 & 13.8 & 9 & 11.0 & 0.579 \\
\hline
\end{tabular}

\# More than one answer. 
Table (5): Total score level of knowledge for COPD elderly patients' at Assuit University Hospital, 2019.

\begin{tabular}{|c|c|c|c|c|c|c|c|c|c|c|c|c|c|c|c|}
\hline \multirow{3}{*}{ Items } & \multicolumn{5}{|c|}{ Pre-test } & \multicolumn{5}{|c|}{ Post-test (2 Months) } & \multicolumn{5}{|c|}{ Post-test (6 Months) } \\
\hline & \multicolumn{2}{|c|}{ Study $n=87$} & \multicolumn{2}{|c|}{ Control $n=82$} & \multirow{2}{*}{$\begin{array}{c}\text { P. } \\
\text { valve }\end{array}$} & \multicolumn{2}{|c|}{ Study $n=87$} & \multicolumn{2}{|c|}{ Control $n=82$} & \multirow{2}{*}{ P. value } & \multicolumn{2}{|c|}{ Study $n=87$} & \multicolumn{2}{|c|}{ Control $n=82$} & \multirow{2}{*}{$\begin{array}{c}\mathbf{P} . \\
\text { value }\end{array}$} \\
\hline & No & $\%$ & No & $\%$ & & No. & $\%$ & No. & $\%$ & & No & $\%$ & No. & $\%$ & \\
\hline \multicolumn{16}{|c|}{ Knowledge level } \\
\hline Poor & 84 & 96.6 & 80 & 97.56 & \multirow{3}{*}{0.946} & 5 & 5.7 & 80 & 97.56 & \multirow{3}{*}{$<0.001 * *$} & 10 & 11.5 & 79 & 96.34 & \multirow{3}{*}{$<0.001 * *$} \\
\hline Fair & 3 & 3.4 & 2 & 2.44 & & 8 & 9.2 & 2 & 2.44 & & 15 & 17.2 & 3 & 3.66 & \\
\hline Good & 0 & 0.0 & 0 & 0.00 & & 74 & 85.1 & 0 & 0.00 & & 62 & 71.3 & 0 & 0.00 & \\
\hline Mean \pm SD & \multicolumn{2}{|c|}{$23.75 \pm 8.9$} & \multicolumn{2}{|c|}{$23.15 \pm 7.29$} & 0.633 & \multicolumn{2}{|c|}{$119.69 \pm 16.95$} & \multicolumn{2}{|c|}{$23.15 \pm 7.29$} & $<0.001 * *$ & \multicolumn{2}{|c|}{$100.83 \pm 14.51$} & \multicolumn{2}{|c|}{$23.74 \pm 9.01$} & $<0.001 * *$ \\
\hline
\end{tabular}

Table (6): Total score level of practice for COPD elderly patients' at Assuit University Hospital, 2019.

\begin{tabular}{|c|c|c|c|c|c|c|c|c|c|c|c|c|c|c|c|}
\hline \multirow{3}{*}{ Items } & \multicolumn{5}{|c|}{ Pre-test } & \multicolumn{5}{|c|}{ Post-test (2 Months) } & \multicolumn{5}{|c|}{ Post-test (6 Months) } \\
\hline & \multicolumn{2}{|c|}{ Study $n=87$} & \multicolumn{2}{|c|}{$\begin{array}{c}\begin{array}{c}\text { Control } \\
n=82\end{array} \\
\end{array}$} & \multirow{2}{*}{$\begin{array}{c}\text { P. } \\
\text { value }\end{array}$} & \multicolumn{2}{|c|}{$\begin{array}{c}\text { Study } \\
\mathbf{n}=87\end{array}$} & \multicolumn{2}{|c|}{$\begin{array}{c}\begin{array}{c}\text { Control } \\
n=82\end{array} \\
\end{array}$} & \multirow{2}{*}{ P. value } & \multicolumn{2}{|c|}{ Study n=87 } & \multicolumn{2}{|c|}{$\begin{array}{c}\text { Control } \\
n=82\end{array}$} & \multirow{2}{*}{ P. value } \\
\hline & $\begin{array}{c}\mathbf{N} \\
\mathbf{0}\end{array}$ & $\%$ & No. & $\%$ & & $\begin{array}{l}\mathbf{N} \\
\mathbf{0}\end{array}$ & $\%$ & No & $\%$ & & No & $\%$ & No & $\%$ & \\
\hline \multicolumn{16}{|c|}{ Practical level } \\
\hline Poor & 84 & 96.55 & 80 & 97.56 & \multirow[b]{2}{*}{0.946} & 0 & 0.00 & 80 & 97.56 & \multirow{2}{*}{$<0.001 * *$} & 0 & 0.0 & 80 & 97.56 & \multirow{2}{*}{$<0.001 * *$} \\
\hline Faire & 3 & 3.45 & 2 & 2.44 & & 3 & 3.45 & 2 & 2.44 & & 4 & 4.6 & 2 & 2.44 & \\
\hline Mean \pm SD & \multicolumn{2}{|c|}{$7.15+3.13$} & \multicolumn{2}{|c|}{$6.93 \pm 2.68$} & 0.625 & \multicolumn{2}{|c|}{$41.01+2.21$} & \multicolumn{2}{|c|}{$6.93 \pm 2.68$} & k0.001** & \multicolumn{2}{|c|}{$40.86+3.19$} & \multicolumn{2}{|c|}{$7.33 \pm 2.59$} & $<0.001 * *$ \\
\hline
\end{tabular}

** Significant difference at p. value $<0.01$

Table (7): Respiratory function outcomes for COPD elderly patients' at Assuit University Hospital, 2019.

\begin{tabular}{|c|c|c|c|c|c|c|c|c|c|c|c|c|c|c|c|}
\hline \multirow{3}{*}{ Items } & \multicolumn{5}{|c|}{ Pretest } & \multicolumn{5}{|c|}{ Posttest (2 Months) } & \multicolumn{5}{|c|}{ Posttest (6 Months) } \\
\hline & \multicolumn{2}{|c|}{ Study $\mathbf{n = 8 7}$} & \multicolumn{2}{|c|}{$\begin{array}{c}\begin{array}{c}\text { Control } \\
n=82\end{array} \\
\end{array}$} & \multirow{2}{*}{$\begin{array}{c}\text { P. } \\
\text { value }\end{array}$} & \multicolumn{2}{|c|}{ Study n=87 } & \multicolumn{2}{|c|}{$\begin{array}{c}\text { Control } \\
\mathrm{n}=82\end{array}$} & \multirow{2}{*}{ P.value } & \multicolumn{2}{|c|}{ Study $n=87$} & \multicolumn{2}{|c|}{ Control $\mathrm{n}=82$} & \multirow[t]{2}{*}{$\begin{array}{c}\mathrm{P} . \\
\text { value }\end{array}$} \\
\hline & No. & $\%$ & No & $\%$ & & No. & $\%$ & No & $\%$ & & No. & $\%$ & No. & $\%$ & \\
\hline \multicolumn{16}{|c|}{ Oxygen saturation:- $\mathrm{SaO2}$} \\
\hline$<90 \%$ & 76 & 87.4 & 71 & 86.6 & \multirow{3}{*}{0.882} & 0 & 0.0 & 36 & 43.9 & \multirow{3}{*}{$\begin{array}{c}<0.001 \\
* *\end{array}$} & 0 & 0.0 & 46 & 56.1 & \multirow{3}{*}{$<0.001 * *$} \\
\hline $90-94 \%$ & 11 & 12.6 & 11 & 13.4 & & 58 & 66.7 & 44 & 53.7 & & 6 & 6.9 & 34 & 41.5 & \\
\hline \multirow[t]{2}{*}{$95-100 \%$} & 0 & 0.0 & 0 & 0.0 & & 29 & 33.3 & 2 & 2.4 & & 81 & 93.1 & 2 & 2.4 & \\
\hline & \multicolumn{2}{|c|}{ Mean \pm SD } & \multicolumn{2}{|c|}{ Mean \pm SD } & & \multicolumn{2}{|c|}{ Mean \pm SD } & \multicolumn{2}{|c|}{ Mean \pm SD } & & \multicolumn{2}{|c|}{ Mean \pm SD } & \multicolumn{2}{|c|}{ Mean \pm SD } & \\
\hline $\begin{array}{l}\text { Respirato } \\
\text { ry rate }\end{array}$ & \multicolumn{2}{|c|}{$28.47 \pm 3.43$} & \multicolumn{2}{|c|}{$28.8 \pm 3.48$} & 0.531 & \multicolumn{2}{|c|}{$25.36 \pm 2.91$} & \multicolumn{2}{|c|}{$28.6 \pm 2.27$} & $<0.001 * *$ & \multicolumn{2}{|c|}{$22.89 \pm 2.58$} & \multicolumn{2}{|c|}{$29.44 \pm 3.11$} & $<0.001 * *$ \\
\hline $\begin{array}{l}\text { Incentive } \\
\text { Spirometer }\end{array}$ & \multicolumn{2}{|c|}{$589.66 \pm 147.88$} & \multicolumn{2}{|c|}{$589.02 \pm 128.63$} & 0.976 & \multicolumn{2}{|c|}{$813.79 \pm 136.55$} & \multicolumn{2}{|c|}{$497.56 \pm 227.15$} & $<0.001 * *$ & \multicolumn{2}{|c|}{$1065.52 \pm 169.7$} & 234.1 & \pm 294.48 & $<0.001 * *$ \\
\hline $\begin{array}{l}\text { Dyspnea } \\
\text { scale }\end{array}$ & 3.48 & $=0.5$ & 3.5 & & 0.184 & 2.69 & 0.47 & & \pm 0.55 & $<0.001 * *$ & 2.23 & $=0.42$ & 3.7 & \pm 0.45 & $<0.001 * *$ \\
\hline $\begin{array}{l}\text { Peak flow } \\
\text { meter }\end{array}$ & 112.4 & 31.88 & 116. & $=40.34$ & 0.442 & 156. & \pm 32.17 & 102. & $4 \pm 35.4$ & $<0.001 * *$ & 215.0 & \pm 45.7 & 86.5 & \pm 40.71 & $<0.001 * *$ \\
\hline
\end{tabular}




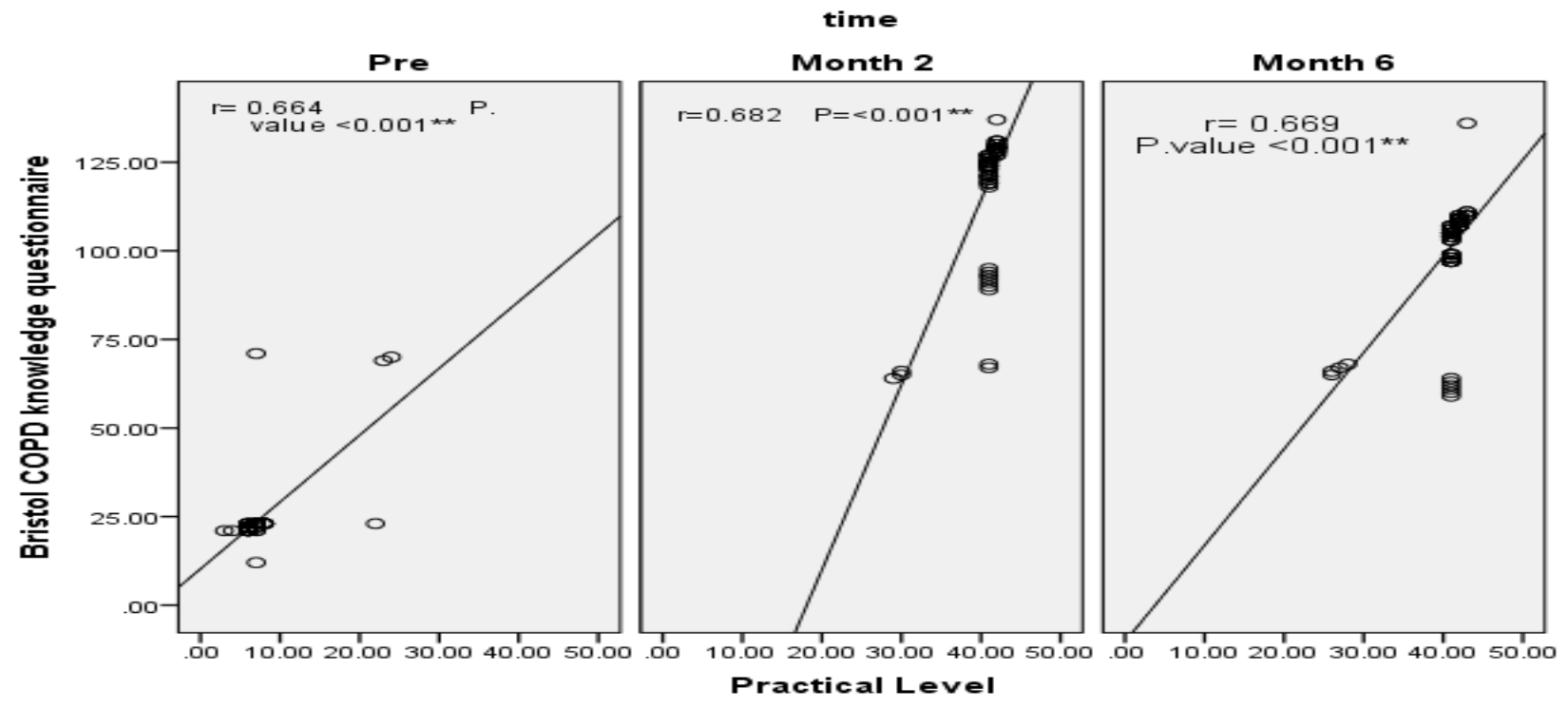

figure (1): Spearman's correlation between total score of knowledge and total score of practice of COPD elderly patients' at Assuit University Hospital, 2019.

Table (1): Showed that distribution of socio demographic data among studied COPD elderly patients. The mean age's $\pm \mathrm{SD}(65.08 \pm 5.12)$ years old, $(75.9 \% \quad \& 70.7 \% \quad$ respectively) were male, $(63.1 \% \& 73.2 \%) \quad$ were illiterate and $(81.6 \% \& 90.2 \%)$ were living in rural area.

Table (2): It was evident that dyspnea and cough were the main complain for COPD elderly patients as a health history in both groups $(100 \%)$. There were statistically significant differences between two groups as regard to time of cough, the length of hospital stay and patient seeks medical advice during 6 months (Follow up period).

Table (3): It was observed hypertension was the most common comorbidities of past history between the study group and control group (65.5\%\& 63.4\%), followed by diabetes mellitus (47.1\%\&46.3\% respectively), and (70.1\%\&70.7\%) of studied population were smokers.

Table (4): Regarding to occupational hazards to dust\& smoke were the most common exposure risk factors COPD elderly patients. The majority of COPD were exposed to dusts due to agricultural crops and smoke inside house $(93.1 \% \& 83.9 \%)$ of the study group and (86.6\% \&90.2\%)of control group). No statistically significant differences were detected between two groups regarding to their occupational and environmental hazards.

Table (5): Illustrated that there was statistically significant difference between total score of knowledge for study group than control group after application the nursing protocol(pre, month 2 and month 6) $\mathrm{P}=(<0.001 * *)$.
Table (6): Presents that there were statistically significant differences in improvement the practical level for study group than in control group (pre, month 2 and month 6) $\mathrm{P}=<0.001 * *$.

Table (7): Illustrated that there were statistically significance difference in study group than in control group (pre, 2months and 6months) $\mathrm{p}=<0.001 *$.

Figure (1): Presents that there was significantly positive correlation between total score of knowledge and total score of practice of study group (pre, 2 months and 6 months).

\section{Discussion}

COPD is recognized as a multicomponent disease, despite being defined by the presence of persistent airflow limitation and normal breathing and is not fully reversible. As the disease progresses, patients develop systemic manifestations; among them exercise intolerance, peripheral muscle dysfunction and exacerbations that often require hospitalization. Dyspnea is the main symptom and causes progressive loss functional capacity until even the simplest activities of daily living are affected (Franssen et al., 2018).

Application of nursing protocol helps the patient maintain the knowledge and the skills required to follow those medical therapies and health behavior changes required to achieve optimal outcomes. Engaging COPD elderly in activities that promote adequate inhalation, positions and postural drainage techniques and physical activity prevents adverse 
health outcomes (Ibrahim \& Abd El-Maksoud, 2018).

Therefore, this study was conducted to evaluate the impact of implementing designed nursing protocol on improving respiratory function of elderly patients' with COPD. The finding of this study covered three main areas: Elderly patient's socio-demographic data, assessment patient's condition and effect of applied nursing protocol on the following: knowledge, practice and respiratory function outcomes.

Based on the results of the present study, the sociodemographic characteristics of studied population revealed that more than studied population lies between (60-65year) years old. This was in agreement with Mohamed et al., (2017) the study done in Egypt, who reported that the age of more than half of the patients with COPD were more than 60years. The may explained by effect of age related changes in respiratory system, these physiologic, cellular, and immunologic changes that occur during aging contribute to the development of lung disease such as COPD (Bowdish, 2019).

Regarding gender, two thirds of the studied sample was males. This finding due to the higher prevalence of COPD due to the high frequency of smoking among men and the frequent occupational exposures to irritating work environment, while contradicted with Center of Disease Control and Prevention (2018) reported that females are more likely to have COPD than males due to indoor pollution, WHO, (2017). Also it was reported that COPD was more common in men previously, but due to comparatively high level of consumption of tobacco smoking and indoor air pollution among women the disease now affects men and women almost equally.

In the current study, more than two third of control group and nearly two third of study group were illiterate as regarded to the educational level, which could contribute to poor health awareness. This finding was agreeing with an Egyptian study done by Mohammad et al., (2018) in Assuit University Hospital who reported that two thirds of both groups COPD patients' were illiterate. Lack of awareness and knowledge about COPD are major reasons of delay or incorrectly manage COPD.

Regarding residence, the current study showed that majority of the studied sample was living in rural area; the same finding is in accordance with Ibrahim \& Abd El-Maksoud, (2018) stated that three quarters of their study subjects were living in rural areas and one quarter was living in urban. Another Egyptian study done by Badway et al., (2016) indicated that the prevalence of COPD is more between rural than urban population. In the same line other study done in china by Fang et al., (2018).The prevalence of COPD in rural was significantly higher than in urban. This is related to inadequate health services in these places; moreover, patients in these areas are exposed to many chemical substances used in farming and building in addition to fumes from burning agriculture wastes and dry plants and this increases the risk of chest diseases.

Concerning occupation, more than one third of the studied sample was farmers; the same finding is in the same line with Badway et al., (2016) mentioned that the high prevalence of COPD among farmers this due to exposure to irritants at their work places causing serious lung damage as most of those patients were working in the agriculture sector, exposure to air pollutants, rice grass burning, using wood, and agricultural crop residues, which lead to greater destruction of airway with more chest symptoms. Concerning the marital status more than two third of study group was married. This finding was agree with Ibrahim \& Abd El-Maksoud, (2018) who reported that more than half of the study sample was married.

The result of present study revealed that, the majority of studied sample were very low socioeconomic level of studied participants. Socioeconomic status (SES) is a strong social determinant of health. This finding was in agreement with foreign study done by Grigsby et al., (2016) who stated that, lower financial status is an important risk factor for respiratory disorder with incidence and increase cases of COPD. Low income makes the patient unable to seek medical advice and to buy the medication.

The current study demonstrated that hypertension and diabetes mellitus are the most comorbidity of the elderly patients with COPD. These results were similar to the findings of an Egyptian study done by Farag et al., (2018) mentioned that hypertension and diabetes mellitus are the most recorded comorbidities of the patients with COPD. Comorbidity is highly prevalent in COPD elderly patients and $84 \%$ of patients have one or two comorbidity factors.

In the present study, more than half of the studied subjects were smokers. The highest percentages of smokers were excessive smokers. This is in harmony with Mohamed et al., (2017) mentioned that more than half of their study subjects were current smokers. Tobacco is considered a major risk factor and important initial diagnostic for COPD. This due to most of patients was heavy smoker shisha and cigarettes.

In the present study about one third of studied sample was passive smoking and they also developed COPD. This may be related to exposure to passive smoking, environmental and occupational exposure to various pollutants, irritants, dusts and gases. This finding coincides with the fact that, the secondhand smoke 
exposure may influence the development and the progression of COPD and its health outcomes. The Egyptian woman expose to passive smoking from smokers who lived with in the same house such as her husband and sons.

The present study noted that the most common risk factors of COPD in both groups related to occupational hazards were dust and smoke. In the same line Saad \& Desoky, (2018), found more than two third of studied patients had occupational exposure in their work environment. Concerning environmental hazards, the majority of COPD elderly patients were exposed to dusts due to agricultural crops and smoke inside house. In the same line Mohammad et al., (2018) found that the most common risk factors of COPD were smoking, air pollution and dust. The majority of studied sample were very low socioeconomic and farmers in addition of poor housing, poor education, poor nutrition and working in agriculture these are the most important risk factors contributing to develop of COPD.

As regards signs and symptoms of COPD, all of patients suffered from dyspnea and chronic cough, and the majority of them complained large amount sputum. These results were similar to the findings of, an Egyptian study done by Badway et al., (2016) \& AlKarn et al., (2018) they reported that, the majority of COPD patients had dyspnea, cough, wheezing chest, sputum, and restlessness. These symptoms were strongly associated with the presence of COPD. It was found that most of the patients had a disease for more than 7 years and two-thirds of them were hospitalized before about three times or more. This reflects the chronicity of the disease and the frequent exposure acute exacerbations that may progress to respiratory failure.

Regarding the patients' level of knowledge pre implementation, the findings of the present study indicated that, the majority of the COPD patients had poor knowledge regarding management of COPD. These findings were consistent with Sharma et al., (2016) and Fromer, (2014), they reported that most of the COPD patients had less knowledge regarding COPD. Additionally, Mohamed et al., (2017) reported that none of the studied group had satisfactory knowledge at pre intervention. This is related to illiteracy, lack of health literacy about prevention and COPD management. Inadequate health services in rural places and lack of studies that aim to improvement elderly knowledge about COPD. Implementation of the educational program, the study showed that there was statistically significant improvement in total score of knowledge, where most of the patients had good knowledge regarding COPD. These results were similar to the findings of Ibrahim
\& Abd El-Maksoud, (2018), they mentioned the majority of patients $(95 \%)$ had poor knowledge, and all of them had unsatisfied knowledge regarding COPD before implementation.

Immediately post implementation, 2 and 6 months of the nursing protocol, the present study showed statistically significant improvement in total score of knowledge regarding COPD. These results were consistent with to the findings of Amer et al., (2018), reported that, all of the studied patients showed highly significant differences in knowledge level improvement after program intervention. This is reflecting the positive effect of the continuous educational sessions to meet the needs of COPD patients. Although the researcher chooses the suitable method of education through used simple pictures and video were very useful in elderly education. The researcher also done immediate posttest to ensure the elderly gained the important knowledge about COPD management.

As regard patients' total practice, there was poor level of practice pre implementation of COPD nursing protocol. After intervention, the study showed statistically significant improvement in total score practice, where the majority of patients had satisfied and good practices at immediate, 2 and 6 months post program. These findings were in accordance with Mohamed et al., (2017) \& Amer et al., (2018), they reported the continuous practicing of breathing exercise, coughing exercise which affects positively their performance by making their breathing more controlled and they become more efficient in removing sputum. The researcher done immediate posttest to ensure the elderly learned with a good manner through demonstration and redemonstration of each step in practical part and continuous training sessions.

The current study illustrated that, there was statistically significant difference of reduce and improvement the level of dyspnea for COPD patient's post implementation of COPD nursing protocol than pre. This finding is congruent with the finding an Egyptian study done by Saad \& Desoky (2018), \& AlKarn et al., (2018) they reported that, there was decrease in the dyspnea severity after rehabilitation program including breathing exercise. This may explained by, the effective continuous practicing of breathing exercises has a positive effect on increasing gas exchange, lowering respiratory rate, increasing tidal volume, and activity of inspiratory and expiratory muscles.

The current study founded that, there were significant positive correlation between the total score of knowledge and practice pre, post and follow up the intervention protocol in study group. These findings 
were in consistent with Fouad et al., (2016), mentioned that there was relation between knowledge and practice about COPD with a significant value between pre, post and follow up the intervention program in study group than control group. This may explained by, the continuous elderly education has a positive effect on knowledge and practice level.

\section{Conclusion}

Based on the study findings, it is concluded that the knowledge and practice regarding COPD management among elderly patients before implementation of the nursing protocol were poor and sever dyspnea. Start application of nursing protocol for elderly patients with COPD has positive effect on improving knowledge, practice and clinical respiratory outcomes as dyspnea grade, oxygen saturation and reduce the number of hospital readmission.

\section{Recommendations}

Based on the result of the present study, the following recommendations are suggested:

1- Continuous educational program for patients with COPD should be applied periodically to improve knowledge, practice and respiratory function outcomes for those patients.

2- The COPD elderly patients' should be followed up with comprehensive health team includes the following: pulmonologist, respiratory nurse, psychiatrist, dietitian, physiotherapist and pharmacotherapies.

3- Home visit and telephone follow up is very essential to manage COPD patients.

\section{Reference}

1. Al Karn A., Hassan W., Abo El Fadl A., \& Mahmoud M., (2018): Effectiveness of pulmonary rehabilitation on pulmonary function parameters and dyspnea in patients with stable chronic obstructive pulmonary disease, Egypt J Bronchol; 12(2): 149-153.

2. Amer F., Eldakhakhny A., Ahmed A., \& Taha N., (2018): Effect of Nursing Intervention Program on Patients knowledge and practice regarding Breathlessness in patients with Chronic Obstructive Pulmonary Disease, Zagazig Nursing Journal; 14(1): 7692.

3. American Lung Association, (2018):Inhaler Device Assessment Tool. Available at: http://www.lung.org/.

4. Badway M., Hamed A., \& Yousef M., (2016): Prevalence of chronic obstructive pulmonary disease in Qena governorate. Egyptian Journal of Chest Diseases and Tuberculosis; 65(1): 29-34.

5. Bowdish, D., (2019): The Aging Lung: Is Lung Health Good Health for Older Adults, Chest Journal; 154 (3):391-400.

6. Centers for Disease Control and Prevention, (2018): Chronic obstructive pulmonary disease. Available at: http://www.cdc.gov.

7. Central Intelligence Agency, (2020): Egypt Demographics Profile 2020, Available In: https://www.indexmundi.com/egypt/demograp hics_profile.html.

8. Dimitrova A., Izov N., Maznev I., Vasileva D., \& Nikolova M., (2017): Physiotherapy in Patients with Chronic Obstructive Pulmonary Disease, Macedonian Journal of Medical Science; 5(6): 720-723.

9. Du W., Liu J., Zhou J., Ye D., OuYang Y., \& Deng Q., (2018): Obstructive sleep apnea, COPD, the overlap syndrome, and mortality: results from the 2005-2008 National Health and Nutrition Examination Survey, International Journal of COPD; 2018(13),665674.

10. El-Gilany A., El-Wehady A., \& El-Wasify M., (2012): Updating and validation of the socioeconomic status scale for health research in Egypt. East Mediterranean Health J; 18(9):962-968.

11. Fang L., Gao P., Bao H., Tang X., Wang B., Feng Y., (2018): Chronic obstructive pulmonary disease in China: a nationwide prevalence study, The lancet Respiratory Medicine; 6, (6): 421-430.

12. Farag T., Sobh E., Elsawy S., \& Fahmy B., (2018): Evaluation of health-related quality of life in patients with chronic obstructive pulmonary disease, The Egyptian Journal of Bronchology; 12 (3): 288-294.

13. Fouad A., Shafik S., \& Belal S., (2016): Effect of Nursing Intervention on Activities of Daily Living of Older Adults with Chronic Respiratory Impairment, American Journal of Nursing Science; 5(4): 129-140.

14. Fiona W., (2016): The Older Adult Patient, Available at:https://nursekey.com/the-olderadult-patient/\#bib3.

15. Franssen F., Smid D., Deeg D., Huisman M., Poppelaars J., Wouters E., \& Spruit M., (2018): The physical, mental, and social impact of COPD in a population-based sample: results from the Longitudinal Aging Study Amsterdam, npj primary care respiratory medicine;28, (30): 1-6. 
16. Fromer L., (2014): Diagnosing and treating COPD: understanding the challenges and finding solutions, International Journal of General Medicine; 4 (2): 729-739.

17. Global Initiative for Chronic Obstructive Lung Disease (GOLD), (2019): Global strategy for diagnosis, management and prevention of COPD. Available at: http://www.goldcopd.com.

18. Grigsby M., Siddharthan T., Chowdhury M., Siddiquee A., Rubinstein A., Sobrino E., Miranda J., Bernabe-Orti A., Alam D., \& Checkley W., (2016): Socioeconomic status and COPD among low- and middle-income countries, Intentional Journal of Chronic Obstructive Pulmonary Dis, 11(5): 2497-2507.

19. Hun Lee S., Yim S., \& Kim H., (2016): Aging of the respiratory system, Kosin Medical Journal; 31(1):11-18.

20. Ibrahima R., \& Abd El-Maksoud M., (2018): Effect of educational programs on knowledge and self-management of patients with chronic obstructive pulmonary disease,Egyptian Nursing Journal; 15:246-257.

21. Jubran A., (2015): Pulse Oximetry: Uses, Readings, and How It Works. Available at: //www.healthline.com/health/pulseoximetry\#takeaway.

22. Knight J., \& Nigam Y., (2017): Anatomy and physiology of ageing 2: the respiratory system, Nursing Times; 113(3): 53-55.

23. Li P., Gong Y., Zeng G., Ruan L., \& Li G., (2016): A new mode of community continuing care service for COPD patients in China: participation of respiratory nurse specialists, Intentional Journal of Clinical and Experimental Medicine; 8(9): 15878-15888.

24. Meiner S., (2018): Gerontological Nursing, $6^{\text {th }}$ Ed, Respiratory function; chapter 22, Elsevier, Pp. 422-435.

25. Miller, C., (2019): Nursing for wellness in older adults.8thEd. Respiratory function in older adult; chapter 5, Wolters Kluwer, Philadelphia, Pp67-71.

26. Miravitles M., \& Anzueto A., (2017): Chronic Respiratory Infection in Patients with Chronic Obstructive Pulmonary Disease: What Is the Role of Antibiotics?,Int J MolSci ; 18(7): 1344.

27. Mohamed D., Ahmed S., Mohamed A., \& Abdel Rahman A., (2017): Effect of care protocol on the knowledge, practice and clinical outcomes of patients with chronic obstructive pulmonary disease, Journal of Nursing Education and Practice; 7(2):107-116.
28. Mohammad M., Mohammad Z., \& ElShinnawy O., (2018): Effect of Clinical Pathway Implementation on Outcomes of Patients with Chronic Obstructive Pulmonary Disease, UN published Doctoral Thesis, Assuit University, Faculty of Nursing, and Egypt.

29. Nishiyama O., Taniguchi H., Kondoh Y., Kimura T., Kato K., Kataoka K., Ogawa T,Watanabe F \& Arizono S., (2010): A simple assessment of dyspnea as a prognostic indicator in idiopathic pulmonary fibrosis. EurRespir J 36:1067-1072.

30. Rawal G., and Yadav S., (2015): Nutrition in chronic obstructive pulmonary disease: A review,Journal of Transitional Internal Medicine; 3(4): 151-154.

31. Restrepo R., Wettstein R., Wittnebel L., \& Tracy M., (2011): Incentive Spirometry: 2011, Respirtory Care; 56(10):1600-1604.

32. Roberto B., Beatriz A., and Megan D, (2016): Self-Management and Quality of Life in Chronic Obstructive Pulmonary Disease (COPD): The Mediating Effects of Positive Affect, Journal of Patient Education and Counseling, 99, (4), 617-623.

33. Royal College of Nursing, (2016): Protocols. Available at: https://rcni.com/hostedcontent/rcn/first-steps/protocols.

34.Saad A., \& Desoky G.,(2018): The effect of breathing exercises on the degree of dyspnea and activities of daily living for patients with chronic obstructive pulmonary disease, IOSR Journal of Nursing and Health Science (IOSRJNHS);7(5):PP 01-16.

35. Said A., Ewisb A., Omran A., Magdya M., and Saleeb M., (2015): Prevalence and predictors of chronic obstructive pulmonary disease among high-risk Egyptians, Egyptian Journal of Bronchology; 9 (1): 27-33.

36. Sarkar M., Bhardwaz R., Madabhavi I., \& Modi M., (2019): Physical signs in patients with chronic obstructive pulmonary disease, Lung India; 36(1): 38- 47.

37. Scullion J., (2018): The Nurse Practitioners' Perspective on Inhaler Education in Asthma and Chronic Obstructive Pulmonary Disease, Canadian Respiratory Journal; Volume 2018, Article ID 2525319, 1-9 pages.

38. Sharma M., Kumar A., \& Venkateshan M., (2016): Effectiveness of self-instructional module on knowledge of self-care management of chronic obstructive pulmonary disease among patients with chronic obstructive pulmonary disease. International Journal of 
Research in Medical Sciences, 4(5), 16041608.

39. Smeltzer S., \& Bare B., (2016): Textbook of medical surgical nursing (10 th ed.). Philadelphia: Lippincott Company, 568-96.

40. Tudorache E., Fildan A., Frandes M., Dantes E., \& Tofolean D., (2017): Aging and extra pulmonary effects of chronic obstructive pulmonary disease, Clinical Interval Aging; 12: 1281-1287.

41. White R., Walker P., Roberts S., Kalisky S., \& White P., (2006): Bristol COPD Knowledge Questionnaire (BCKQ): testing what we teach patients about COPD, Chronic Respiratory Disease journal, 3, 123-131.

42. WHO, (2017): Chronic obstructive pulmonary disease (COPD).Available at:https://www.who.int/news-room/factsheets/detail/chronic-obstructive-pulmonarydisease-(copd).

43. World Population Prospects, (2018): Ageing, Available at: http://www.un.org/en/sections/issuesdepth/ageing/.

44. Yorke J., Prigmore S., Hodson M., Stonham C., Long H., Bellhouse S., Fletcher M., \& Edwards S., (2017): Evaluation of the current landscape of respiratory nurse specialists in the UK: planning for the future needs of patients, BMJ Open Respiratory Research ; 4(1):1-8. 